\title{
Improved Creatine Stability and pH Profile for Kre-Alkalyn
}

\section{Jeff Golini*}

All American Pharmaceutical and Natural Foods Corporation Billings, Montana, USA

\begin{abstract}
Creatine modification for commercialization has included many variations to increase its stability. The current report assesses the stability of a sodium bicarbonate buffered creatine sold under the brand name Kre-Alkalyn under various conditions. Kre-Alkalyn is shown to have a good 6 year stability and shelf life under accelerated testing. It maintains a high pH over time compared to normal creatine and can be augmented with additional stabilizing buffers. This stability and buffering profile may serve useful in providing continued creatine availability.
\end{abstract}

Keywords: Kre-Alkalyn; Creatine; ATP depletion; Creatinine; Sodium carbonate; $\mathrm{pH}$ stability

\section{Introduction}

Creatine (N-(aminoiminomethyl-N-methyl glycine) is an important energy producing amino acid based metabolite produced in the liver, kidneys, and pancreas and commonly used by the muscles [1-3]. Creatine in various forms is used as a supplement to increase athletic performance [4-6]. Creatine is pivotally important in delaying ATP depletion during anoxia or ischemia through the creatinephosphocreatine system, for example [7]. Yet its stored shelf life and half-life in the stomach play a role in its bioavailability after ingestion. Previous reports suggest that the degradation of creatine results from $\mathrm{pH}$ changes $[2,8,9]$. Indeed at normal physiological $\mathrm{pH}, 10 \%$ of creatine has been suggested to convert to creatinine, it's most common byproduct [10].

In this report a commercial creatine monohydrate powder buffered with sodium carbonate $\left(\mathrm{Na}_{2} \mathrm{CO}_{3}\right)$ to a $\mathrm{pH}$ of 12 (Kre-Alkalyn', All American Pharmaceuticals) was tested for stability and examined for conserved buffering capacity when compared to traditional creatine. Though understudied in the context of creatine, changes in acid-base regulation have also been shown to effect protein-protein interactions [11], mitochondrial efficiency [12], and cellular signaling and proliferation [13,14]. Furthermore, Kre-Alkalyn increased cytoprotection against cisplatin-induced cytotoxicity compared to conventional creatine in $293 \mathrm{~T}$ human kidney cells [8], suggesting another possible utility of in vivo creatine buffering.

Herein, two commercialization properties of Kre-Alkalyn are examined. Specifically, the stability and conversion of Kre-Alkalyn to creatinine and $\mathrm{pH}$ profile compared to traditional creatine.

\section{Methods}

\section{Stability testing procedure}

1.5 grams of Kre-Alkalyn ${ }^{\circledR}$ was mixed in water. Real Time and Accelerated testing was performed. The same lot was used for both tests.

Step 1: Kre-Alkalyn ${ }^{\oplus}$ powder was assayed for purity, 1.5 grams of Kre-Alkalyn powder was added to $4 \mathrm{oz}$ of water and stored in lab for real time testing, and 1.5 grams of Kre-Alkalyn powder was added to 4 $\mathrm{oz}$ of water and put into incubator for accelerated testing.

Step 2: Both groups of products were tested at 30 day segments.

\section{FTNIR analysis}

Identification performed by FTNIR, against in-house external library standards obtained from Sigma and produced by HPLC. Quantification by FTNIR against external library standards obtained from Sigma and produced by HPLC (Bran and Luebbe InfraProver II FTNIR).

\section{HPLC analysis}

Analysis performed by HPLC using Intersil ODS- $25 \mu \mathrm{m}(250 \times 4.6$ $\mathrm{mm}$ ) and $25 \mathrm{~min}$. gradient elution with $0.1 \%$ phosphoric acid buffer in $\mathrm{H} 20$ and $0.1 \%$ phosphoric acid in acetonitrile. External reference standards obtained from Sigma-Aldrich.

\section{Stomacher}

Previously described by Golini [8], but consisting of a glass vessel and liquid acid to mimic the acidic environment of the stomach, creatine or Kre-Alkalyn was first added to water as described above and then added to the acid and $\mathrm{pH}$ was assessed over time.

\section{pH analysis}

Creatine and Kre-alkalyn solutions were tested for changes in $\mathrm{pH}$ using a standard calibrated $\mathrm{pH}$ meter (ATLAS Bioscience; Tuscon, AZ). Three solutions were added to Kre-Alkalyn; hydrochloric acid (0.1 ml-1M), sodium hydrogencarbonate/sodium carbonate (11.7/ 13.7 (ml-1M)), and ethanolamine/ethanolamine hydrochloride (18.6/ $6.3(\mathrm{ml}-1 \mathrm{M}))$.

\section{Results}

The shelf stability of Kre-Alkalyn is conserved during both real-time and accelerated testing of creatine to creatinine conversion. Only during the accelerated stability test was there a small indication of creatine to creatinine conversion at 0.055 after 150 days, the equivalent to 5 years of real time, and $0.1 \%$ after 180 days, the equivalent to 6 years of realtime. It has been established that creatine breakdown is a function of $\mathrm{pH}$ [2]. Using a systematic mock-up of a stomacher, described above, it was shown that Kre-Alkalyn maintained a significantly higher $\mathrm{pH}$ than

*Corresponding author: Jeff Golini, PhD, All American Pharmaceutical and Natural Foods Corporation Billings, Montana, 59105, USA, Tel: 406245-5793; E-mail: jeffg@allamericanpharmaceutical.com

Received August 06, 2015; Accepted November 05, 2015; Published November 15,2015

Citation: Golini J (2015) Improved Creatine Stability and pH Profile for Kre-Alkalyn. J Biosens Bioelectron 6: 187. doi:10.4172/2155-6210.1000187

Copyright: (c) 2015 Golini J. This is an open-access article distributed under the terms of the Creative Commons Attribution License, which permits unrestricted use, distribution, and reproduction in any medium, provided the original author and source are credited. 
traditional creatine, in three separate reagents tested. A slow decline from highly basic $\mathrm{pH}$ (12) to neutral $\mathrm{pH}$ (7) after 45 minutes with KreAlkalyn in a $0.1 \mathrm{M} \mathrm{HCl}$ solution was observed. Even with the addition of hydrogencarbonate/sodium carbonate or ethanolamine/ethanolamine hydrochloride, commonly used biopharmaceutical buffers, which increased the rate of $\mathrm{pH}$ reduction, Kre-Alkalyn maintained higher $\mathrm{pH}$ levels than traditional creatine?

\section{Discussion}

It has previously been reported that the commercially available sodium bicarbonate buffered creatine, Kre-Alkalyn, may provide cytoprotective properties, above and beyond traditional creatine, when used in the presence of cytotoxic agents such as those used during chemotherapy [8]. In this report, Kre-Alkalyn, was assessed for soluble stability during both a real-time ( 1 year) and accelerated ( 6 year) trial. During these trials only a small fraction of Kre-Alkalyn was converted into creatinine at the end of the accelerated 6 year trial. A much higher rate of degradation was observed with traditional creatine in similar trials $[15,16]$.

Furthermore, the conversion of creatine to creatinine has been directly linked in vivo to changes in $\mathrm{pH}$. As such, stability under acidic conditions, reminiscent to the stomach, were conducted with traditional and buffered Kre-Alkalyn. The results of these tests suggested that the $\mathrm{pH}$ buffering capacity of Kre-Alkalyn will maintain a much higher $\mathrm{pH}$ in an acidic environment than traditional creatine, even in the presences of additional acid buffering reagents. First water solubilized Kre-Alkalyn was examined in the presence of $\mathrm{HCl}$ and only slowly declined to a neutral $\mathrm{pH}$ after a period of 45 minutes, ample time for the creatine contained in the supplement to leave the stomach and enter the blood-stream. Second, when tested in the presence of acidifying buffers, Kre-Alkalyn maintained a significantly higher $\mathrm{pH}$ over 45 a minute period then traditional creatine in a normal $\mathrm{HCl}$ solution.

The findings of this report suggest that Kre-Alkalyn maintains its stability when mixed with water over a significant time frame and should provide a sustained basic $\mathrm{pH}$ in the acidic environment of the stomach necessary for reducing creatine to creatinine conversion. Thus, based on the stability profiles presented, Kre-Alkalyn should provide superior availability in vivo to traditional creatine commonly used in sports supplements.

\section{References}

1. Golini J (2006) The Dangers of Creatinine. Brandenton, FL.

2. Jäger R, Purpura M, Shao A, Inoue T, Kreider RB (2011) Analysis of the efficacy, safety, and regulatory status of novel forms of creatine. Amino Acids 40: $1369-1383$.

3. Brosnan JT, Brosnan ME (2010) Creatine metabolism and the urea cycle. Mol Genet Metab 100 Suppl 1: S49-52.

4. Cooper R, Naclerio F, Allgrove J, Jimenez A (2012) Creatine supplementation with specific view to exercise/sports performance: an update. J Int Soc Sports Nutr 9: 33

5. Moraes Rd, Van Bavel D, Moraes BS, Tibiriçá E (2014) Effects of dietary creatine supplementation on systemic microvascular density and reactivity in healthy young adults. Nutr J 13: 115.

6. Antonio J, Ciccone V (2013) The effects of pre versus post workout supplementation of creatine monohydrate on body composition and strength. $J$ Int Soc Sports Nutr 10: 36

7. Garbati P, Salis A, Adriano E, Galatini A, Damonte G, et al. (2013) A new method to synthesize creatine derivatives. Amino Acids 45: 821-833.

8. Golini J (2015) The effect of an alkaline buffered creatine (Kre-Alkalyn ${ }^{\circledR}$ ), on cell membrane behavior, protein synthesis, and cisplatin-mediated cellular toxicity Integrative Molecular Medicine 2: 214-218.

9. Hageböck M, Stahl U, Bader J (2014) Stability of creatine derivatives during simulated digestion in an in vitro model. Food Funct 5: 359-363.

10. MacNeil L, Hill L, MacDonald D, Keefe L, Cormier JF, et al. (2005) Analysis of creatine, creatinine, creatine- $\mathrm{d} 3$ and creatinine-d 3 in urine, plasma, and red blood cells by HPLC and GC-MS to follow the fate of ingested creatine-d3. J Chromatogr B Analyt Technol Biomed Life Sci 827: 210-215.

11. Klimov VV, Baranov SV (2001) Bicarbonate requirement for the water-oxidizing complex of photosystem II. Biochim Biophys Acta 1503: 187-196.

12. Bishop DJ, Thomas C, Moore-Morris T, Tonkonogi M, Sahlin K, et al. (2010) Sodium bicarbonate ingestion prior to training improves mitochondrial adaptations in rats. Am J Physiol Endocrinol Metab 299: E225-233.

13. Steegborn C, Litvin TN, Levin LR, Buck J, Wu H (2005) Bicarbonate activation of adenylyl cyclase via promotion of catalytic active site closure and metal recruitment. Nat Struct Mol Biol 12: 32-37.

14. Golini J, Jones WL (2014) Buffered vs. Non-Buffered Aliphatic Fatty Acids and their Anti-Proliferative Effects in Human Tumor Cell Lines. Single Cell Biology 4: 107.

15. Ganguly S, Jayappa S, Dash AK (2003) Evaluation of the stability of creatine in solution prepared from effervescent creatine formulations. AAPS PharmSciTech 4: E25.

16. Uzzan M, Nechrebeki J, Zhou P, Labuza TP (2009) Effect of water activity and temperature on the stability of creatine during storage. Drug Dev Ind Pharm 35: 1003-1008. 